BULLETIN Bulletin hispanique

HISPANIQUE Université Michel de Montaigne Bordeaux

$115-2$ | 2013

Les traductions vieillissent-elles ?

\title{
A tradução líquida
}

o texto vivo

Nicolau Dols e Gabriel de la S. T. Sampol

\section{(2) OpenEdition}

Journals

Edição electrónica

URL: http://journals.openedition.org/bulletinhispanique/2732

DOI: 10.4000/bulletinhispanique.2732

ISSN: 1775-3821

Editora

Presses universitaires de Bordeaux

Edição impressa

Data de publição: 28 Dezembro 2013

Paginação: 557-563

ISBN: 978-2-86781-908-7

ISSN: 0007-4640

Refêrencia eletrónica

Nicolau Dols e Gabriel de la S. T. Sampol, «A tradução líquida », Bulletin hispanique [Online],

115-2 | 2013, posto online no dia 14 fevereiro 2017, consultado o 05 maio 2019. URL : http://

journals.openedition.org/bulletinhispanique/2732; DOI : 10.4000/bulletinhispanique.2732 


\title{
A tradução líquida: o texto vivo
}

\author{
Nicolau Dols \& Gabriel de la S.T. Sampol \\ Universitat de les Illes Balears
}

La version d'une auvre difficile à l'instar du Livre de l'intranquillité de Fernando Pessoa manifeste particulièrement la tension entre un texte fidèle à l'original et un texte acceptable dans la tradition littéraire réceptrice. Les auteurs analysent ce fait à partir de leur expérience de traduction dudit livre en catalan.

Mots-clés : traduction, Pessoa, Livre de l'intranquillité.

La versión de una obra difícil como el Libro del desasosiego de Fernando Pessoa evidencia especialmente la tensión entre un texto fiel al original y un texto aceptable en la tradición literaria receptora. Los autores analizan este hecho a partir de su experiencia de traducción de dicho libro al catalán.

Palabras claves : translation, Pessoa, Libro del desasosiego.

The conflict between fidelity to the source text and acceptability in the target-language culture shows up in the translation of a difficult text like the "Book of Disquiet" by Fernando Pessoa. We will analyse those tensions, arisen in the process of translating Pessoa's work into Catalan.

Keywords: Translation, Pessoa, Book of Disquiet.

$\mathrm{N}$ este debate sobre se uma tradução realmente envelhece ou não, e se, no final, concluirmos efectivamente que sim, temos a esperança de que a nossa (publicada no ano de 2002) ainda não necessite de ser reformada.

Mas antes de falarmos sobre o envelhecimento da tradução, temos de falar do envelhecimento e do rejuvenescimento do texto original, o qual é mais que evidente no caso do Livro do Desassossego, como veremos e como já explicou com todo o detalhe e em primeira pessoa Richard Zenith.

Este ponto vê-se ainda reforçado pelas extraordinárias expectativas produzidas pela edição póstuma e tardia do Livro. A edição e as traduções desta obra estão 
cheias de paradoxos. O primeiro é que este livro, quando é publicado pela primeira vez, nasce já como um clássico consagrado, ainda que desconhecido. Este facto provoca traduçôes simultâneas e a possibilidade de se estabelecerem comparaçóes entre elas.

O Livro do Desassossego é um original difícil. Há nele uma coerência de forma e de sentido que não se pode ignorar quando se decide empreender a sua tradução. Como já dissemos noutro lugar, o leitmotiv da obra é a dificuldade de se particularizar relativamente aos outros e ao que a rodeia. Isto faz com que os cenários predilectos do livro sejam os próprios das mudanças de consciência, sempre frágil, sempre mutável, afinal líquida. Há uma desagregaçáo do eu que tem muitas consequências na visão do mundo que chega até nós, e que afecta também -e isto é o mais importante no caso do tradutor-a língua. Esta já não concebida como uma instituição mas, convertida em movimento contínuo, é tomada e largada. Não é possível retratar num momento fixo esta língua que não é a da voz narradora, porque a voz narradora, simplesmente, se dilui ou quer causar-nos a sensação de que já se diluiu.

$\mathrm{Na}$ análise que faz da versão alemá, Herculano de Carvalho estabelece uma classificação das dificuldades de tradução do texto:

A lingua, com efeito, deste livro inacabado e para que o autor não chegou sequer a elaborar um plano ou esquema que servisse de guia aos futuros possiveis editores (notemos que a maioria dos fragmentos não está sequer datada), caracteriza-se por abundantes e frequentes anomalias em relação à norma, e até ao sistema (prefiro dizer "esquema") do português, que consistem; $1 .^{\circ}$ ) em palavras forjadas pelo autor, como são desdormir - "Durmo e desdurmo". (99) -, completidão, inevitabilizar, mesmamente, outrarse, desverde, menos-calores n. pl., imbastantemente; 2.0) combinaçöes sintácticas inesperadas, como fazer não fazer nada, casas ingremadas (de íngreme), branco branco (em que o segundo lexema, como adjectivo, classifica o primeiro, substantivo), diferenças socalcadas da casaria, nuvens átonas; $3 .^{\circ}$ ) construçōes verbais não consentidas pela norma, como "repugno a vida... repugno o sonho" (96), "Os idyllios longinquos... doem-me esta hora análoga por dentro" (176), "Chego à foz da Rua da Alfândega,... e, ao clarear-me o Terreiro do Paço,..." (181), "soffro-me o envolucro de mim mesmo" (427). (Carvalho, 147-148)

Além dos aspectos que cita Herculano de Carvalho, é preciso falarmos dos anacolutos que se presumem no texto e outros casos de agramaticalidade -quem sabe se voluntária-, muito diferentes da antigramaticalidade, às vezes indicada directamente pelo autor, como faz em alguns casos de referências metalinguísticas muito conhecidas de todos (uso transitivo do verbo ser: «me sou»; ou a violaçấo da concordância de género: «uma rapaz»).

Às dificuldades já expostas e que se centram numa liberdade criativa que, além do conteúdo expresso, afecta também o código, aditam-se o carácter fragmentário do material e as possibilidades diversas de configuração que permite e que, de facto, tem permitido em ediçôes sucessivas. Antes de comentarmos as dificuldades de carácter filológico que produz a fixação do texto, talvez fosse recomendável olharmos para os problemas - a partir de um ponto de vista exclusivamente tradutológico. Herculano de Carvalho termina a sua análise 
com referências às duas classes de transporte linguístico que distinguia Coseriu:

É claro que, como sucede com efeito, estas anomalias podem dificultar a compreensão do texto a um leitor, mesmo culto, de língua portuguesa, elas representam maiores dificuldades ainda para o tradutor que pretenda fazer dele, não uma simples Übersetzung (digamos, tradução) mas uma verdadeira Übertragung (digamos, versão). (Carvalho, 148).

Naturalmente, sempre há mais duma possibilidade de tradução, que não são só duas, mas praticamente infinitas. É verdade que habitualmente, ao falar-se de possibilidades de tradução, tem-se reduzido o problema a um dualismo que contempla apenas os dois extremos dum continuum que vai desde a tradução mais literal e supostamente fiel em grau máximo ao original até a uma adaptação aos gostos da época e da tradição literária destinatária. São a «Übersetzung» e a "Übertragung» coseriuanas a que se referia Herculano de Carvalho. Mas também são os conceitos de «subsidiary translation» e «substitutory translation» de Nord, que já apareceram em House sob a forma de "tradução aberta» I «tradução coberta». Na realidade, um texto longo e bastante difícil como o Livro do Desassossego póe à prova qualquer propósito reducionista dos tipos possíveis de tradução. Em Dols \& Mansell (2009) já se destacou de maneira formal como o processo de traduçáo é um processo de tomada de decisôes a partir de alternativas (Pym) que multiplicam as opçóes possíveis (Holmes). Não há uma só tradução possível, nem dois extremos duma corda, mas um conjunto numeroso de opçóes que frequentemente se implicam entre elas. Com o Livro do Desassosego tudo isto que se diz das traduçôes possíveis parece que é também aplicável a um espaço intersticial que separa a autoria e a tradução, que é o da fixação do texto. E o texto tem sido fixado de maneiras diferentes, por este factor e também pelo factor independente da diversidade de traduçôes possíveis.

Em relação às diferentes edições do original, inconcluso e não definitivamente ordenado pelo autor, como sabemos, aparecem com diferentes adscriçóes de textos ao corpus, com diversas ordenaçôes e com leituras muito divergentes de trechos concretos, provocadas sobretudo pela quase ilegível letra pessoana. No caso do nosso livro, a escolha do texto inicial é ainda mais importante do que noutros casos por causa das diferentes soluçóes de leitura do manuscrito e, na realidade, este pode ser um factor ainda mais capital do que a ordenação, a exclusão ou a inclusão de alguns trechos (aliás, nunca conheceremos a opinião de Pessoa sobre a configuração final do livro). São um exemplo extraordinário disto mesmo as leituras sucessivas «entre um milionário americano, com bens em Inglaterra, na Suiça, e o chefe socialista da aldeia - não há diferença de qualidade [...]» e "entre um milionário americano, um César ou Napoleão, ou Lenine, e o chefe socialista da aldeia [...]». Em referência ao Livro do Desassossego podemos falar, com toda a propriedade, de envelhecimento do original, pois pode-se considerar que determinadas ediçóes, meritórias e imprescindíveis no seu momento (estamos a pensar, por exemplo, na clássica de António Quadros), têm sido superadas por outras, que fizeram o processo inverso de 
rejuvenescimento a que nos referíamos ao princípio. Temos que confessar que a edição de que partiu a nossa versão já envelheceu, por causa da revisão que fez Zenith na sua reedição de 2009. Envelheceu, consequentemente, a nossa tradução? Talvez Dorian Gray tenha a resposta.

$\mathrm{Na}$ nossa opinião, e seguindo algumas coisas que já foram sabiamente ditas neste colóquio, o que tem importância, se estamos a falar na vigência ou envelhecimento das traduçóes, é a relação do tradutor com o texto. Pode ser completa e fecunda, no caso de o tradutor ser um leitor eficiente, ou pode ser incompleta. A exposição é incompleta, em primeiro lugar, se a tradução for mediatizada. Um exemplo são as traduçóes do chinês de Carner, Manent ou Ferraté, que produziram bons textos poéticos em cataláo baseados na literatura chinesa, mas sem que conhecessem a língua original. É bom comparar, como já fizemos noutro lugar, as traduções de Manent antes e depois de conhecer a sinóloga Dolors Folch. Em segundo lugar, a exposição ao original é incompleta -e isto é exactamente o que aconteceu com a nossa tradução- se o original for incompleto ou estiver ainda em processo de criação: a versão dum texto como O livro do desassossego é difícil talvez porque o autor fez que o texto continuasse sempre aberto, numa reconfiguração contínua. A tradução, em consequência, não pode ser mais do que uma fotografia fixa dum texto em movimento.

Com uma estranha coerência, as dificuldades para determinar o texto inicial coincidem com a dificuldade intrínseca da obra. É certo que a determinação do texto inicial é a funçâo do editor literário, e que o tradutor se limita simplesmente a segui-lo neste campo. Nesse sentido, a única responsabilidade do tradutor deve ser a da escolha do texto inicial entre os diversos que foram já propostos. A tradução pode já ter nascido velha se a escolha inicial tiver privilegiado um texto já «envelhecido». É interessante saber o que sucede com essas traduçóes. Por exemplo, no caso da literatura catalá, a versão do Livro do Desassossego anterior à nossa (de Manuel de Seabra e Vimala Devi, de 1990), já não se reedita; mas, no caso da castelhana, a versão de Ángel Crespo (de 1983) ainda hoje é reeditada. (É necessário precisar, aliás, que nos dois casos se tratam de editoras diferentes, mas que a versão catalã de Seabra-Devi consiste numa antologia).

No nosso caso, a decisão sobre o texto inicial vinha já dada: a editorial seguiu o conselho do professor Cuadrado e já nos contratou para traduzirmos o texto fixado por Richard Zenith (1999). Desta maneira não tivemos a responsabilidade da escolha. É verdade que nessa altura a escolha era mais simples do que hoje, quando as novas ediçôes de Zenith (2009), de Sobral Cunha (2008) e de Jerónimo Pizarro (2010) incrementam a complexidade inicial da selecção. Mas já dissemos que o Dr. Cuadrado se converteu para nós na estrela de Belém e decidimos segui-lo sem dúvida nenhuma.

Também a pressão editorial pela edição deste clássico moderno pode condicionar o texto final. O desejo do tradutor é trabalhar, em primeiro lugar, com um texto inicial tâo definitivo quanto seja possível (já falámos nisso) e, em segundo lugar, sem a pressão dos editores. Este segundo ponto assentou numa luta contra determinadas imposiçóes estilísticas que ainda hoje não 
estamos em condições de aceitar, e apesar de elas não afectarem num grau deveras importante o resultado, impedem que consigamos identificar-nos completamente com a tradução. Sáo talvez todos esses factores que contribuem para atribuir uma responsabilidade colectiva à obra literária recebida pelo leitor. Nesse sentido, o envelhecimento ou a permanência duma tradução não podem atribuir-se unicamente ao trabalho do tradutor. A questão paraliterária dos prazos e as urgências editoriais também não são nem agradáveis para o tradutor nem edificantes para o público.

Contudo, não é totalmente certo que a escolha que fez a editorial do texto inicial nos libertasse de responsabilidade, ao menos aos olhos da crítica: Toni Ibáñez, tradutor para o catalão de $A$ educação do estóico, acusou-nos por termos suprimido na nossa tradução a famosa frase «Deus é bom, mas o diabo também não é mau», uma frase que já na edição de 1999 não aparecia, e que Richard Zenith publicou como aforismo independente em Aforismos e afins (Assírio \& Alvim, 2003).

As diferenças na determinação do texto inicial e as dificuldades de tradução de muitos fragmentos provocaram uma diversidade de traduçôes que permitem as comparações. Um exemplo são as diferentes soluções oferecidas pelas traduções castelhana e catalã do texto: a tradução de Cuadrado e a nossa, devem resolver os mesmos problemas com ferramentas diferentes. No caso da frase original «é estio mas verão", a tradução castelhana tem a vantagem de terem as duas línguas, a portuguesa e a castelhana, as palavras «estio»/«estío», e «verão»/«verano». Para os tradutores catalães a dificuldade está em achar a fórmula de expressar alguma coisa semelhante, mas sem ter-se disponível um par de palavras para expressar a mesma relação de significado. A solução, arriscada sem dúvida, foi traduzir "és estiu, però no gaire», retraduzível como 'é estio, mas não demasiado', com a atenção posta nas diferenças de intensidade sublinhadas na frase original. Os jogos de palavras ou de conceitos têm sido sempre um desafio para o tradutor porque não jogam só com as palavras, mas também com outros aspectos da sua cultura e das suas tradiçôes. Entre línguas próximas às vezes é fácil que esses aspectos léxicos e culturais coincidam, mas não é sempre assim, e é então que as dificuldades aparecem. Por exemplo, no caso doutras traduções que fizemos, o jogo que estabelece Saramago entre as palavras «cadeira» e «cair» em português, e «cadere» em latim no conto "Cadeira», em Objecto Quase, é imediatamente trasladável para o catalão, com os equivalentes exactos «cadira» e «caure», mas tem dificuldades evidentes para ser traduzido noutras línguas próximas como a castelhana ou a francesa (ainda que «chaise» tenha a mesma raiz latina que "cadeira» e "cadira»). Ou, em outro exemplo, a tradução catalã das Memórias de Voltaire não pode trasladar directamente a burla feita a um prelado que assinava como "l'anc. évêque de Mirepoix», mas com uma caligrafia que sugeria a leitura "l'âne évêque de Mirepoix». Neste caso, e tendo em conta que as palavras "antic» e «ase» são demasiado diferentes em catalão, a solução foi substituir o «asno» pelo "pato» («ànec»), uma figura igualmente irrisória quando é associada à dignidade dum mitrado. 
Ainda que o Livro do Desassossego seja um clássico contemporâneo, também é um anticlássico porque voluntariamente se afasta da tradição, e é desse afastamento que com frequência nascem os problemas do tradutor. É assim que a versão dum texto especialmente difícil como o Livro do Desassossego revela melhor que nenhum outro a tensão entre a fidelidade ao original e a necessidade de adequar o texto final à tradiçáo literária de destino. Diante dos anacolutos e outros casos de possível agramaticalidade (distinta da antigramaticalidade de que já falámos) o tradutor sente a tentação de os transportar para a tradução, e simultaneamente e no sentido contrário, a tentação de náo os ter em consideração e corrigir o estilo do autor.

Deixámos para o final desta reflexão um elemento que ataca o leitor em primeiro lugar: o título. A versão catalã de Seabra e Devi adoptou a solução de Llibre del desfici. "Desfici» foi bem aceite e tinha já criado uma certa tradição, ao ponto de a editora nos perguntar se íamos conservar o título. "Desfici», «desassossec», «neguit», «intranquil.litat», «inquietud» e algumas mais são palavras que, ainda que diferentes, têm muito em comum e eram todas candidatas a aparecer no título da nossa tradução. É verdade que gostávamos de «desfici» pela sonoridade e poeticidade (já apareceu nas obras de grandes poetas como Jacint Verdaguer ou Joan Alcover), mas em comparação com o original tinha a dificuldade de não contar com um antónimo da mesma raiz lexical: não existe "*fici» em oposiçáo a "desfici». O problema era idêntico com «neguit». Ficavam entâo "desassossec», «intranquil.litat» e «inquietud». Apesar do escasso uso popular de «desassossec», finalmente a decisão foi tomada por fidelidade ao original, e a tradução ficou como Llibre del desassossec.

A conclusão do nosso trabalho como tradutores é que, na verdade, trata-se do livro do desassossego do tradutor, mas é um desassossego feliz, um desassossego criativo que obriga o tradutor, como masoquista literário que é, a superar uns obstáculos atrás dos quais descobrimos novas visôes da obra original. Pessoa não nos desilude nunca.

\section{Bibliografía}

Carvalho José G. Herculano de, "O Livro do Desassossego / Das Buch der Unruhe ", in António Franco (ed.), Duas línguas em contraste: Portugués e Alemão / Actas do $1^{\circ}$ Coloquio Internacional de Linguistica Contrastiva Português-Alemão (Anexo III da Revista da Faculdade de Letras), Porto, Instituto de Estudos Germanísticos da Faculdade de Letras, 1989, pp. 147-169.

Dols Nicolau, Richard Mansell, "Resolving meaning conflict in translation: an Optimality approach to verse translation ", Linguistica antverpiensis, NS 7, 2009, pp. 45-74.

Holmes James S., «Forms of Verse Translation and Translation of Verse Form », in Translated! Papers on Literary Translation and Translation Studies, Amsterdam, Rodopi, 1988, pp. 23-33.

House Juliane, A Method for Translation Quality Assessment, Tubinga, TBL Verlag Gunter Narr, 1977. 
Nord Christiane, Translation as a Purposeful Activity, Manchester, St. Jerome, 1997.

Paes Sidónio de Freitas Branco, "Livro do Desassossego. Reflexóes dum leitor pessoano sobre várias versões ", Colóquio/Letras 155-156, Jan. 2000.

Pessoa Fernando, Llibre del desfici, traducció de Vimala Devi i Manuel de Seabra, Barcelona, Proa, 1990.

Pessoa Fernando, Livro do desassossego, edição de Richard Zenith, Lisboa, Assírio e Alvim, 1999 (última edição, corrigida, 2009).

Pessoa Fernando, Libro del desasosiego, traducción de Perfecto E. Cuadrado, Barcelona, Acantilado, 2002.

Pessoa Fernando, Llibre del desassossec, traducció de Nicolau Dols i Gabriel de la S.T. Sampol, Barcelona, Quaderns Crema, 2002.

Pym Anthony, Translation and Text Transfer. An Essay on the Principles of Intercultural Communication, Frankfurt am Main, Peter Lang, 1992.

Saramago José, Objecte quasi, traducció de Gabriel de la S.T. Sampol, Barcelona, Proa, 2000.

Voltaire, Memòries per servir per a la vida de M. de Voltaire, escrites per ell mateix, traducció de Gabriel de la S.T. Sampol, Muro (Mallorca), Ensiola, 2005. 